\title{
Age Limits in Law: Between Behavioural Science and Human Rights
}

\author{
Frank Weerman \& Jolande uit Beijerse*
}

Keywords: age limits, behavioural science, human rights, age, juvenile justice

Age is one of the most important factors shaping our lives and societies. As babies and children, we are dependent on parents or caretakers. As we grow older, we go to school and follow-up education, develop cognitively and emotionally and become increasingly autonomous. Later in life, we may get jobs, start families and take on responsibilities of all kind. At the end of our lives, we may have become wiser, but we also usually take a step back in our responsibilities as we retire and our physical condition becomes weaker. Therefore, many societal institutions and social arrangements are focused on certain ages or stages in life, and this is also reflected in law. In various legal areas, there are rules and procedures that are applicable only to certain ages as they are related to varying responsibilities, levels of cognition or socio-emotional capacities to make and understand decisions. Age plays a role in judicial decisions regarding culpability or sanctions and regarding qualification for certain services or rights. In accordance with human rights conventions, there are even special areas of law that are devoted to certain age groups, for example juvenile justice for young offenders or care proceedings in family law.

How age should matter in judicial decisions and at what age the age limits should be set is a complicated issue. It can be approached from different legal angles, including arguments drawn from legal philosophy about responsibility, autonomy, accountability, and protection. But also empirical insights on how young people develop into responsible and autonomous adults need to be taken into account. These insights can be drawn from a wider array of behavioural scientific disciplines, including biology, developmental psychology and the neurosciences. For example, there is an ongoing discussion on the judicial consequences of new insights from studies in neuropsychology showing that brain development still continues until the age of 25 . Some scholars argue that this needs to be taken into account in criminal justice decision-making. At the same time, research in developmental psychology shows that adolescents and also chil-

\footnotetext{
Frank Weerman is endowed professor Youth Criminology at the Erasmus School of Law and senior researcher at the NSCR (Netherlands Institute for the Study of Crime and Law Enforcement). Jolande uit Beijerse is associate professor Criminal Law and Criminal Procedure at the Erasmus School of Law.
}

dren seem to be more able to make balanced and reasonable decisions about their own family situation, their health and their identity than often assumed, which may have important implications for their position in civil law and voting procedures. The interplay between empirical insights from behavioural science and legal arguments means that the question of whether and how age should matter in law is best served with a multidisciplinary perspective.

Despite the progress in the behavioural sciences, it is often difficult to determine the age at which individuals have reached certain levels of cognition and responsibility that are needed to take autonomous decisions and the age at which they can be held accountable for crimes and be punished as adults. This may even differ from person to person and between social categories or between cultures. For this reason, there is a lot of space for discussion. Age limits in law are seldomly uncontested: policymakers and legal scholars often disagree on the age limits that suit the situation the best. As a result, differences in age limits and other legal arrangements related to age exist between countries and sometimes between jurisdictions. Age limits also differ between areas of law, such as criminal law, family law, civil law and labour law.

In this special issue, we bring together seven articles that deal with various age limits and age considerations in several areas and disciplines: international law, youth justice and criminal law, civil law and family law, voting rules, European labour law and health law. Authors from different countries were asked to write a contribution on age limits in legal areas and to include a discussion based on a combination of normative arguments, comparative analyses and empirical insights on human development. This has resulted in a varied thematic issue that starts with two overarching contributions. The first one is that of Rap, Schmidt \& Liefaard, which reflects on the fundamental principles and practical application of age limits in several legal areas, based on international children's rights law. The authors focus on the UN Convention on the Rights of the Child (UNCRC), in which protection as well as participation and autonomy are central issues. They observe an inconsistent application of age limits and conclude that the UN Committee on the Rights of the Child struggles to provide comprehensive guidance, resulting in open norms and leeway to set age limits based on practical and political reasons. The second overarching contribution is a comparative analysis of Leenknecht, Put \& 
Veeckmans, in which age limits within the youth justice systems of six different countries are analysed. These include the Netherlands, Northern Ireland and New Zealand, with a low minimum age of criminal responsibility, and Belgium, Austria and Argentina, with a high minimum age of criminal responsibility. The comparison shows that the systems of age limits are far more complex than just lower and upper age limits and that within the justice systems there are several other relevant age limits, such as court age limits and detention institution age limits. The authors end their contribution with a proposal for a coherent conceptual framework on age limits in youth justice.

The next two contributions focus on current developments and discussions on legal age limits in the Netherlands. The contribution of Bruning and Peper shows that in Dutch family (civil) law, there is a tortuous jungle of age limits, exceptions and limitations regarding children's procedural rights. The authors focus on the lower legal age limit for the right of children to be heard according to Article 12 UNCRC and argue that the current age of 12 in Dutch civil law should at least be lowered to the age of eight. They suggest that based on empirical research with a neuropsychological perspective, the best option would be to individually determine the child's competency in each case. On the other hand, they argue that fixed legal age limits have the advantage of a clear system. Instead of organising a system for individual assessments, a system in which the judge can focus on inviting all children from a certain age to be heard in court would be preferable. In a sense, the contribution of Prop, Van der Laan, Barendregt \& Van Nieuwenhuizen evaluates a system in which an opposite direction was chosen. In 2014 the Netherlands broadened the possibility to impose a youth sanction on offenders aged 18 to 22, for young offenders with behavioural problems and developmental stages that would fit juvenile justice better than adult criminal law. But in this law the Dutch government opted for the burden of an individual assessment in each case instead of bringing all young adult offenders to the Youth Court. The authors show that the young adult offenders that were selected committed more offences of a serious nature compared with young adults sentenced with adult sanctions and that the nature of the problems of this selected group was in line with what was intended by this proceeding. However, it is unclear to what extent they were also less developed mentally. The authors observe that the concept of maturity remains elusive and difficult to assess in legal practice and call for more research in this regard.

The last three contributions refer to age limits in three totally different legal areas. Peto addresses the issue of the minimum age for the right to vote and extensively addresses insights from empirical developmental psychology to show that by the age of 16 (if not earlier) individuals have developed all the cognitive components of autonomy, although various other capacities are still evolving. Respect for autonomy requires granting political rights, including the right to vote for this age group.
Ter Haar provides a complete overview of how the European Court of Justice (CJEU) has handled age discrimination regarding employment and labour law. Her qualitative analysis shows that the CJEU seems to follow a 'complete life view' when judging these cases and that an unequal distribution of resources over the course of the life of an individual, or different ages, can be acceptable. The last contribution of Horton is on age limits in healthcare in the United Kingdom, where the National Health Service determines access to a range of health interventions, including infertility services and cancer screening and treatment. The article explores the compatibility of some of the age barriers with UK antidiscrimination law, which has prohibited age discrimination in the provision of public services, including healthcare. Age considerations in care have become even more pressing since the Covid-19 crisis has affected particularly older people and has put pressure on the available health resources.

All in all, this issue shows how insights derived from non-legal disciplines like philosophy and developmental (neuro-) psychology are used to determine legal age limits. At the same time, it also illustrates that even if those insights are clear (which is not always the case), setting legal age limits is still a very complicated process.

One complicating factor is that the way in which age limits in legal systems are set differs from system to system, with far-reaching consequences in practice. Youth justice provides a telling example of this (as illustrated by the contribution by Leenknecht et al. in this issue). When the age limit for being tried as an adult is set at 18 , it is still a question whether the system starts from the age at the date of the trial or at the date of the offence. That makes a big difference because it can sometimes take a year or longer before the trial takes place. Most systems use the date of the offence - but then the problem remains that committing a crime one day before the 18th birthday leads to completely different sanctions than one day later: a more educationfocused youth sanction or an adult sanction with the possibility of life imprisonment. This is one of the reasons why some systems (including the one from the Netherlands; see also the contribution by Prop et al.) created the possibility for ages 18-21 to qualify for youth sanctions and for ages $16-18$ to qualify for adult sanctions. These exceptions clearly illustrate that the legislature should not follow rigid age limits, whether based on insights from behavioural science or not, but always respect the human rights perspective and legal principles. With regard to this, it is noteworthy that the first exception (18-21 years old tried as juveniles) is in accordance with the UNCRC but that the second exception (16- and 17 years old tried as adults) is not.

Another example of the complex relationship between insights from behavioural science and legal age limits is that a balance is needed between clarity and predictability, on the one hand, and a tailored approach, on the other. From a (neuro-)psychological perspective the best option would be to individually determine the adolescent's or child's competency in each case because the 
psychological and neurological development differs from person to person. But from the juridical principle of legality, legal age limits should be clear in the law, and defendants should not be dependent on assessments by a psychologist to be brought to court. This would mean that in youth justice or in family law, it might be better if all children from a young age are heard in court and if all young adult offenders are brought to the Youth Court so that they get a fair chance with a judge who eventually takes the decisions that affect their lives instead of a behavioural scientist.

A last example of the complexity of the subject of this special issue is the apparent contradiction between different legal areas in the consequences of insights from behavioural sciences. In this issue, arguments based on developmental and cognitive psychology and the neurosciences lead to a plea to lower the age to vote to 16 and the age to be heard in court even to 8 . At the same time, findings from the behavioural sciences are used to argue that it is necessary to raise the age to qualify for a youth sanction to 23 .

However, from a human rights perspective, there is no contradiction. All arguments raised in this issue relate to the extension of rights: the right to vote, the right to be heard and the right to qualify for a youth sanction. In the end, then, setting the right age limits seems to be a matter of combining empirical insights from the behavioural sciences with applying recommendations based on human rights. 